\title{
Recent in vitro findings of negative inotropy of pantoprazole did not translate into clinically relevant effects on left ventricular function in healthy volunteers
}

\author{
Wolfgang Schillinger · Nina Hörnes · Nils Teucher $\cdot$ Samuel Sossalla Daniel Sehrt \\ Klaus Jung • Mark Hünlich • Bernhard Unsöld · Bianca Geiling · Giuliano Ramadori • \\ Reinhard Hilgers · Harald Schwörer · Gerd Hasenfuss
}

Received: 4 November 2008/ Accepted: 24 February 2009/Published online: 20 March 2009

(c) The Author(s) 2009. This article is published with open access at Springerlink.com

\author{
Abstract \\ Purpose Reports on cardiac problems with oral proton \\ pump inhibitors have caused extensive safety reviews by \\ the US Food and Drug Administration. We provide addi- \\ tional data on acute cardiac effects of an intravenous \\ application. \\ Methods Echocardiography was performed in 18 healthy \\ volunteers after administration of a common high-dose \\ regimen of pantoprazole ( $80 \mathrm{mg}$ i.v. bolus followed by \\ $8 \mathrm{mg} / \mathrm{h}$ for $1 \mathrm{~h}$ ) or placebo. \\ Design The design included a randomized, double-blind, \\ placebo-controlled cross-over trial. \\ W. Schillinger $(\bowtie) \cdot$ N. Hörnes $\cdot$ S. Sossalla $\cdot$ M. Hünlich \\ B. Unsöld · G. Hasenfuss \\ Herzzentrum, Kardiologie und Pneumologie, \\ Universitätsmedizin Göttingen, Robert-Koch-Str. 40, \\ 37099 Göttingen, Germany \\ e-mail: Wolfgang.Schillinger@medizin.uni-goettingen.de \\ N. Teucher \\ Herzzentrum, Thorax-, Herz- und Gefäßchirurgie, \\ Universitätsmedizin Göttingen, Göttingen, Germany \\ D. Sehrt \\ Zentrum Pharmakologie und Toxikologie, Klinische \\ Pharmakologie, Universitätsmedizin Göttingen, Göttingen, \\ Germany \\ K. Jung $\cdot$ R. Hilgers \\ Medizinische Statistik, Universitätsmedizin Göttingen, \\ Göttingen, Germany \\ B. Geiling \\ Genetische Epidemiologie, Universitätsmedizin Göttingen, \\ Göttingen, Germany \\ G. Ramadori · H. Schwörer \\ Gastroenterologie und Endokrinologie, \\ Universitätsmedizin Göttingen, Göttingen, Germany
}

Results Ejection fraction $(\%$, mean $\pm \mathrm{SE})$ in the treatment group (placebo group) was $60.7 \pm 1.1(61.2 \pm 1.7)$ at baseline, and $62.6 \pm 1.1 \quad(62.1 \pm 1.9), 64.7 \pm 1.6$ $(63.5 \pm 1.3), \quad 62.6 \pm 1.6(61.0 \pm 1.6)$ and $63.0 \pm 1.4$ $(61.8 \pm 1.5)$ at $7.5,15,30$ and $60 \mathrm{~min}$ after bolus application, respectively ( $p=$ n.s.). Similarly, no significant changes were found for cardiac output, cardiac index, blood pressure and heart rate. In contrast, gastric $\mathrm{pH}$ that was used as a treatment control was significantly increased 60 min after the application of pantoprazole as compared to baseline and to placebo.

Conclusions Pantoprazole as injection is safe in healthy subjects with respect to cardiac contractile function. However, in view of recent reports of negative inotropy of the drug, further studies in heart failure patients are required.

Keywords Cardiac output - Myocardial contraction . Heart failure - Cardiotonic agents · Pharmacology

\section{Introduction}

Proton pump inhibitors (PPIs) are extensively used in the treatment of acid-related gastrointestinal diseases [28]. In Germany, anti-ulcer/gastrointestinal reflux products accounted for $€ 1.4$ billion gross pharmacy sales in 2007, and two different PPIs ranked among the 15 top-selling drugs [9]. Three PPIs, namely pantoprazole, omeprazole and esomeprazole, are currently available as intravenous formulations in Europe. The rationale for use has come primarily with the suggested efficacy in reducing rebleeding after endoscopic treatment of bleeding peptic ulcers (e.g., 19, 30). The target goal for gastric $\mathrm{pH}$ in these patients has been suggested to be $>6$ in order to promote 
hemostasis and minimize clot lysis, in contradistinction to the target $\mathrm{pH}$ of $>4$ for preventing stress ulcer in patients, or healing ulcers or reflux esophagitis. As such, the dosing amounts of i.v. PPIs have been higher than that of oral PPIs $[19,28,30]$.

Yet, it has been known for several years that the effects of PPIs are not strictly limited to gastric parietal cells. Relaxation of smooth muscle cells has been implicated from experiments with human and guinea pig airway smooth muscle [23] and isolated arteries from rats [21], guinea pigs and humans [23]. Moreover, we have recently demonstrated negative inotropy of pantoprazole in isolated myocardium of humans and rabbits [25]. This was dosedependent, induced nearly complete inhibition of twitch force at high-doses and was partially reversible. Similar results have been obtained with esomeprazole, which is suggestive of a class effect of PPIs. The subcellular mechanisms of cardiac effects of pantoprazole were distinct from the effects in gastric cells and involved changes in intracellular $\mathrm{Ca}^{2+}$ transients and impaired $\mathrm{Ca}^{2+}$ responsiveness of the myofilaments. Also, we have deduced from the in vitro findings that negative inotropy may be of clinical relevance when using common therapeutic doses [25].

Recent reports on heart-related problems in two small, long-term clinical studies of patients treated with oral PPIs for severe gastroesophageal reflux disease have caused extensive safety reviews by the US Food and Drug Administration (FDA). On December 10, 2007, the FDA concluded that long-term use of oral omeprazole or esomeprazole is not likely to be associated with an increased risk of heart problems [6]. However, none of the evaluated studies was specifically conducted to assess the risk of heart problems and patient follow-up was incomplete. Moreover, studies investigating the acute effects of intravenous high-dose PPIs on left ventricular function are missing. The present study investigated the effects of i.v. pantoprazole on left ventricular function in healthy volunteers using a common high-dose regimen [30]. Echocardiography was used because in clinical practice, the vast majority of clinical decisions involving left ventricular function are based on echocardiographic findings.

\section{Materials and methods}

\section{Participants}

Enrollment of test persons was performed from 15 May 2005 until 27 January 2006 in the Department of Cardiology and Pneumology, University Medical Center Göttingen, Germany. For inclusion and exclusion criteria,
Table 1 Inclusion and exclusion criteria

\begin{tabular}{ll}
\hline Inclusion criteria & Exclusion criteria \\
\hline Age, 18-40 years & History of cardiac disease \\
No clinically overt signs & History of other relevant \\
of heart failure & pre-existing illness \\
Echocardiographic ejection & Pathologic findings in \\
fraction $\geq 55 \%$ & clinical examinations \\
Excellent sonographic & Pathologic \\
conditions & echocardiographic \\
& findings \\
Non-smoker & Pathologic ECG findings \\
& Pathologic laboratory \\
& findings \\
& Pregnancy and lactation \\
& No or insufficient \\
& contraception \\
& Intolerance of pantoprazole \\
& Alcohol or drug abuse \\
\hline
\end{tabular}

see Table 1 . Volunteers were thoroughly examined and routine laboratory parameters, ECG recordings and echocardiography were analyzed. Volunteers were excluded if any pathologic finding was present. Moreover, only subjects with excellent sonographic conditions were included. For baseline characteristics, see Table 2. The study complies with the Declaration of Helsinki. The ethics committee of the University of Göttingen approved the research protocol and informed consent was obtained from all subjects.

Study design, sample size and randomization

A double-blind, placebo-controlled cross-over design was applied [27]. The sample size was calculated according to the change in ejection fraction (EF) as an effect of pantoprazole that was meant to be detected. The expected standard deviation was derived from historical data $[10$, 14]. Assuming a power of 0.90 and an alpha-level of 0.05 , we calculated that 14 subjects would be sufficient for the detection of an absolute difference in EF of $6 \%$. To allow for dropout, ten females and ten males were randomized. Half of each gender group received pantoprazole on study day 1 and placebo on study day 2 (protocol 1), and the other half inversely (protocol 2). Stratified block randomization was used to balance the number of men and women (Fig. 1). During the preliminary examination, a treatment time was assigned to each participant. From this treatment time, a study number was derived, where each study number was assigned to one of the two groups by the statistician beforehand. Two subjects, one female and one male, dropped out because of drug mixup on study day 2 . 
Table 2 Baseline characteristics of healthy volunteers

\begin{tabular}{|c|c|c|c|c|c|}
\hline & $\begin{array}{l}\text { All } \\
n=18\end{array}$ & $\begin{array}{l}\text { Female } \\
n=9\end{array}$ & $\begin{array}{l}\text { Male } \\
n=9\end{array}$ & $\begin{array}{l}\text { Protocol } 1 \\
n=9\end{array}$ & $\begin{array}{l}\text { Protocol } 2 \\
n=9\end{array}$ \\
\hline Age (years) & $24.3 \pm 0.4$ & $24.0 \pm 0.4$ & $24.6 \pm 0.8$ & $24.1 \pm 0.4$ & $24.4 \pm 0.8$ \\
\hline Body mass index $\left(\mathrm{kg} / \mathrm{m}^{2}\right)$ & $22.7 \pm 0.4$ & $21.5 \pm 0.5$ & $23.8 \pm 0.5$ & $22.7 \pm 0.6$ & $22.6 \pm 0.6$ \\
\hline Body surface area $\left(\mathrm{m}^{2}\right)$ & $1.87 \pm 0.03$ & $1.75 \pm 0.01$ & $1.99 \pm 0.03$ & $1.85 \pm 0.05$ & $1.89 \pm 0.05$ \\
\hline \multicolumn{6}{|l|}{ Resting blood pressure (mmHg) } \\
\hline Systolic & $121.3 \pm 1.6$ & $118.3 \pm 2.4$ & $124.2 \pm 2.0$ & $121.7 \pm 2.6$ & $120.8 \pm 2.0$ \\
\hline Diastolic & $69.2 \pm 1.7$ & $70.4 \pm 2.2$ & $67.9 \pm 2.5$ & $72.1 \pm 2.5$ & $66.3 \pm 2.1$ \\
\hline Resting heart rate (/min) & $66.8 \pm 1.5$ & $66.6 \pm 2.1$ & $67.1 \pm 2.1$ & $65.9 \pm 2.1$ & $67.8 \pm 2.0$ \\
\hline Resting ejection fraction (\%) & $60.9 \pm 1.0$ & $61.4 \pm 1.4$ & $60.4 \pm 1.5$ & $60.5 \pm 1.4$ & $61.3 \pm 1.5$ \\
\hline
\end{tabular}

Mean baseline characteristics ( \pm SE) of 18 volunteers are shown. Protocol 1 means persons who were randomized to receive pantoprazole on day 1 and placebo on day 2, and protocol 2 inversely. There were no statistically significant differences between groups

Fig. 1 Flowchart of participation in the study

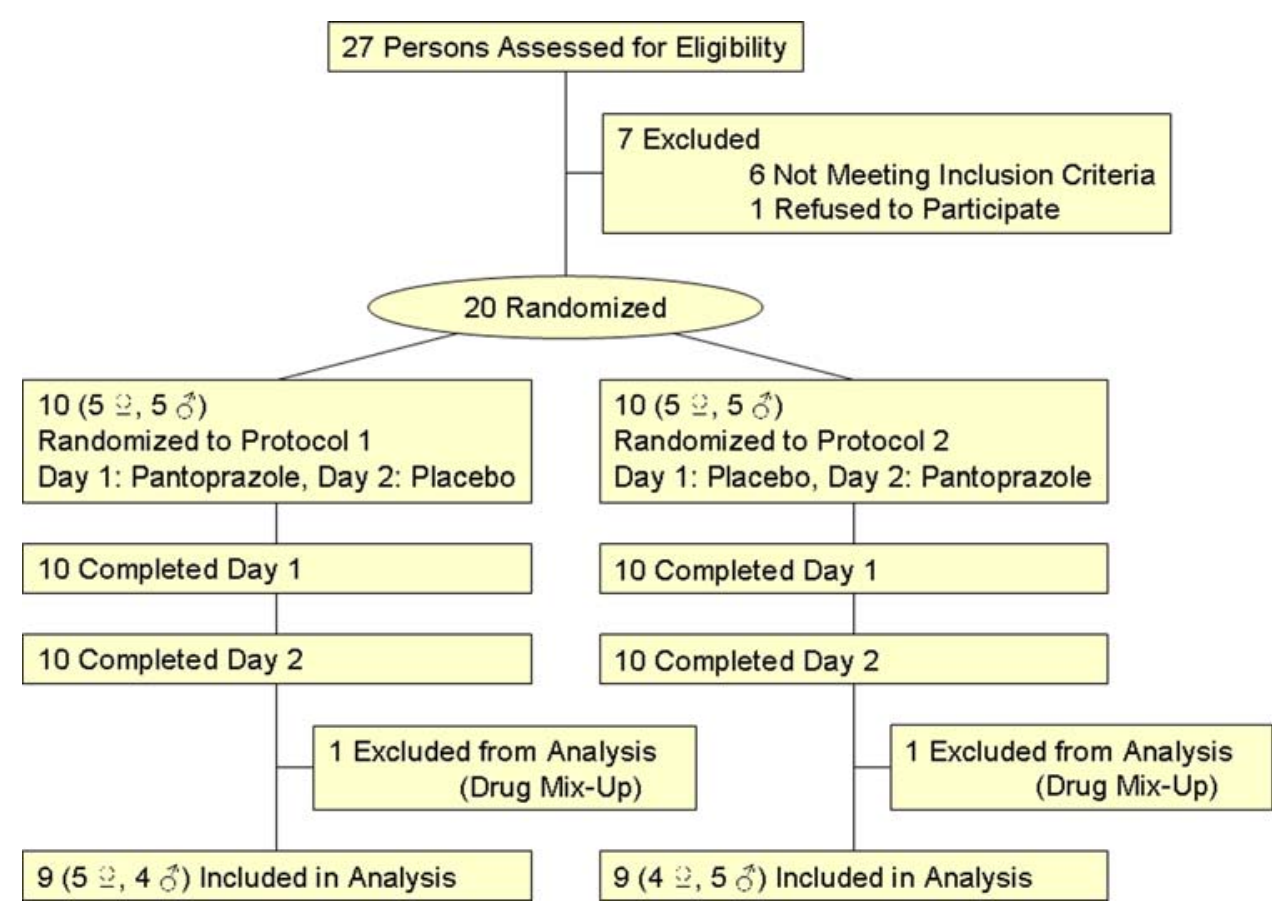

Pharmaceuticals

Pantoprazole sodium powder for injection was purchased from Altana Pharma AG, Konstanz, Germany. NaCl 0.9\% was purchased from DeltaSelect $\mathrm{GmbH}$, Pfullingen, Germany. Preparations of test substances were of identical aspect and were done by the pharmacy of the University Medical Center Göttingen, where also the randomization list was kept.

\section{Gastric pH}

For gastric $\mathrm{pH}$ measurement, a Slimline ${ }^{\circledR}$ single-use $\mathrm{pH}$ catheter (Medtronic GmbH, Düsseldorf, Germany) connected to a Digitrapper ${ }^{\mathrm{TM}} \mathrm{pH} 400$ recorder (Medtronic
GmbH, Düsseldorf, Germany) was used. The display was covered to exclude examiner bias during further measurements. After the study procedure, data were read with Polygram Net ${ }^{\mathrm{TM}} 4.01$ software (Medtronic $\mathrm{GmbH}$, Düsseldorf, Germany). Analyses were performed computerized after completion of the trial.

\section{Holter ECG}

Holter ECG was recorded using a Lifecard CF digital Holter recorder (Spacelabs Healthcare $\mathrm{GmbH}$, Feucht, Germany). Digital data were analyzed after completion of the trial by Pathfinder Digital software (Spacelabs Healthcare $\mathrm{GmbH}$, Feucht, Germany). The mean heart rates for 1-min-intervals were calculated. 
Blood pressure

Non-invasive blood pressure measurements were done using an automatic inflation blood pressure monitor Omron 705IT (Omron Medizintechnik GmbH, Mannheim, Germany).

\section{Echocardiography}

2D- and continuous wave (CW) Doppler echocardiography with standard axis views were performed by one highly experienced cardiologist using a Sonos 7500 (Philips Medizin Systeme GmbH, Hamburg, Germany) ultrasound machine according to the recommendations of the American Society of Echocardiography [10, 18, 22]. For volume measurements, three loops in the apical 4-chamber view were digitally saved at each sample interval during quiet respiration. For measurement of velocity-time integral (VTI), the transducer was angulated to position the path of the CW Doppler in line with the left ventricular outflow tract (LVOT). Three velocity signals at each sample interval were saved. For measurement of LVOT diameter $\left(D_{\mathrm{LVOT}}\right)$, three beats in the parasternal long axis view zoomed on the aortic valve were placed in a cine-loop. $D_{\text {LVOT }}$ was measured at the base of the aortic cusps at peak of systole (aortic valve maximally open), using inner edge to inner edge. The largest of the three measurements was taken and was further used in all serial measurements.

Analyses were performed blinded after completion of the trial using Philips Xcelera 1.2 L4 software (Philips Medizin Systeme GmbH, Hamburg, Germany). Left ventricular volumes were calculated according to the singleplane method of discs [10, 18]. End-diastole was defined as the frame in which the QRS complex appeared. Endsystole was defined by the frame preceding initial early diastolic mitral opening, which corresponded to the smallest visible cavity area. EF was calculated as

$\mathrm{EF}(\%)=100 \times(\mathrm{EDV}-\mathrm{ESV}) / \mathrm{EDV}$

Cross-sectional area (CSA) of LVOT was calculated as $\operatorname{CSA}\left(\mathrm{cm}^{2}\right)=D_{\text {LVOT }}^{2} \times \pi / 4$.

Measurements of CW Doppler velocities were taken from the outer border and the velocity-time integral (VTI) was measured. $\mathrm{CO}$ was calculated as

$\mathrm{CO}(\mathrm{L} / \mathrm{min})=(\mathrm{CSA} \times \mathrm{VTI} \times \mathrm{HR}) / 1000$

at which heart rate (HR) was averaged over $1 \mathrm{~min}$ at each sample interval [22]. Averaged heart rates were similar to the respective instantaneous heart rates measured with the echo machine or the blood pressure monitor. CI was calculated as
$\mathrm{CI}\left[\mathrm{L} /\left(\min \times \mathrm{m}^{2}\right)\right]=\mathrm{CO} / \mathrm{BSA}$

and body surface area (BSA) was calculated from height and weight according to the formula of DuBois and DuBois [4].

Interventions and blinding

Pantoprazole $80 \mathrm{mg}$ given intravenously over $2 \mathrm{~min}$, followed by $8 \mathrm{mg} / \mathrm{h}$ [30] was applied by a Perfusor fm (B. Braun AG, Melsungen, Germany). Alternatively, $\mathrm{NaCl}$ $0.9 \%$ was applied in an identical manner. The test subject as well as the examiner and all assistant personnel were blinded toward the nature of the test substance. All parameters were measured 5-10 min before bolus application (baseline, BL) and 7.5, 15, 30 and 60 min (echocardiography, blood pressure) or continuously thereafter (gastric $\mathrm{pH}$, Holter ECG). Adverse reactions were noted and the intensity was quantified by a numeric analog scale ranging from 1 to 10. Examination with the comparator substance was done after at least 5 and not later than after 14 days.

Statistical methods

Classical cross-over analyses, which account for treatment, period and carry-over effects [27] were performed separately for each point in time. Neither of these effects was statistically significant at an alpha-level of 0.05 (Table 3). In particular, the estimated treatment effects on EF at the single times reached from -1.2 to 0.7 , which is below the expected effect of $6 \%$. For calculating the true power of the cross-over analyses for the detection of EF-changes under treatment, we determined the standard deviation of the measured EFs and proceeded as in the sampling frame. Thus, we received a power of 0.98 for the detection of changes of $6 \%$ with the remaining 18 subjects.

As there was no significant carry-over effect, we combined the two periods and modeled both EF and CI, as a mixture of treatment- and time-effect as well as a (treatment $\times$ time)-interaction. Again, no significant effect could be detected at an alpha-level of 0.05 (Table 4). $\mathrm{pH}$ values between treatment and control group (or between times) were compared by an analysis of variance for longitudinal data. All analyses were carried out using the statistic software $\mathrm{R}$ and SAS. Data are presented as mean $\pm \mathrm{SE}$.

\section{Results}

Basic clinical parameters and adverse reactions

Systolic and diastolic blood pressure measured non-invasively did not show any statistically significant differences 
Table 3 Hemodynamics with pantoprazole

\begin{tabular}{|c|c|c|c|c|c|c|}
\hline & \multicolumn{3}{|l|}{ Mean $( \pm \mathrm{SE})$} & \multicolumn{3}{|c|}{$p$ values of evaluated effects } \\
\hline & Time (min) & $\begin{array}{l}\text { Pantoprazole } \\
n=18\end{array}$ & $\begin{array}{l}\text { Placebo } \\
n=18\end{array}$ & Carry-over & Treatment & Period \\
\hline \multirow[t]{5}{*}{$\mathrm{EF}(\%)$} & BL & $60.7 \pm 1.1$ & $61.2 \pm 1.7$ & 0.55 & 0.69 & 0.69 \\
\hline & 7.5 & $62.6 \pm 1.0$ & $62.1 \pm 1.9$ & 0.85 & 0.54 & 0.29 \\
\hline & 15 & $64.7 \pm 1.6$ & $63.5 \pm 1.3$ & 0.43 & 0.57 & 0.09 \\
\hline & 30 & $62.6 \pm 1.6$ & $61.0 \pm 1.6$ & 0.46 & 0.73 & 0.23 \\
\hline & 60 & $63.0 \pm 1.4$ & $61.8 \pm 1.5$ & 0.88 & 0.96 & 0.70 \\
\hline \multirow[t]{5}{*}{$\mathrm{CO}(\mathrm{L} / \mathrm{min})$} & BL & $5.7 \pm 0.3$ & $5.3 \pm 0.2$ & 0.08 & 0.29 & 0.31 \\
\hline & 7.5 & $5.7 \pm 0.2$ & $5.5 \pm 0.3$ & 0.60 & 0.38 & 0.41 \\
\hline & 15 & $5.5 \pm 0.3$ & $5.3 \pm 0.2$ & 0.39 & 0.23 & 0.88 \\
\hline & 30 & $5.6 \pm 0.3$ & $5.5 \pm 0.2$ & 0.68 & 0.80 & 0.30 \\
\hline & 60 & $5.5 \pm 0.3$ & $5.6 \pm 0.2$ & 0.75 & 0.31 & 0.47 \\
\hline \multirow[t]{5}{*}{$\mathrm{CI}\left[\mathrm{L} /\left(\min \mathrm{m}^{2}\right)\right]$} & BL & $3.0 \pm 0.1$ & $2.8 \pm 0.1$ & 0.05 & 0.38 & 0.22 \\
\hline & 7.5 & $3.0 \pm 0.1$ & $3.0 \pm 0.1$ & 0.61 & 0.54 & 0.40 \\
\hline & 15 & $2.9 \pm 0.1$ & $2.8 \pm 0.1$ & 0.35 & 0.25 & 0.81 \\
\hline & 30 & $3.0 \pm 0.1$ & $2.9 \pm 0.1$ & 0.61 & 0.87 & 0.16 \\
\hline & 60 & $2.9 \pm 0.1$ & $3.0 \pm 0.1$ & 0.79 & 0.42 & 0.38 \\
\hline
\end{tabular}

Mean $( \pm$ SE) are shown. No statistically significant differences were found

BL baseline, EF ejection fraction, $\mathrm{CO}$ cardiac output, $\mathrm{CI}$ cardiac index

Table $4 p$ values in the mixture model analysis

\begin{tabular}{llll}
\hline & Treatment & Point in time & $\begin{array}{l}\text { Interaction } \\
\text { (treatment } \times \text { point in time) }\end{array}$ \\
\hline $\mathrm{EF}$ & 0.46 & 0.07 & 1.0 \\
$\mathrm{CI}$ & 0.30 & 0.42 & 0.49 \\
\hline
\end{tabular}

over 60 min after application of pantoprazole as compared to baseline or to placebo. Similarly, heart rate, which was averaged over $1 \mathrm{~min}$ at each sample interval did not demonstrate any statistically significant change as a result of treatment with pantoprazole or placebo (Fig. 2). Test substances were well tolerated and test persons reported few adverse reactions. Irritation of the throat by the $\mathrm{pH}$ catheter was reported by seven persons with an intensity of 1-5, irritation of the injection site by three (intensity 2-3), abdominal pain by two (2-3), sweetish taste by one (1), and heartburn by one person (2) on a scale of 1-10 each. There was no significant increase of adverse reactions as a result of treatment with pantoprazole compared to placebo.

Left ventricular ejection fraction, cardiac output and cardiac index

Results of echocardiographic evaluation of left ventricular function in the presence of pantoprazole or placebo are summarized in Table 3. There was no statistically significant change in left ventricular EF over $60 \mathrm{~min}$ in subjects receiving a common dosing regimen of pantoprazole when compared to baseline measurements before bolus application. Also, no significant differences in EF were found when compared to placebo infused to the same subjects in an identical manner. In addition, there were no significant changes in $\mathrm{CO}$ and $\mathrm{CI}$ over $60 \mathrm{~min}$ as a result of pantoprazole infusion compared to baseline or compared to placebo.

\section{Gastric $\mathrm{pH}$}

Figure 3 demonstrates a typical gastric $\mathrm{pH}$ profile under treatment with pantoprazole or placebo in the same subject and statistical data of all subjects. At $60 \mathrm{~min}$ after the bolus application of pantoprazole, gastric $\mathrm{pH}$ was $3.9 \pm 0.5$. This was significantly different from baseline $(1.6 \pm 0.1, p<$ $0.001)$ and from placebo $(1.7 \pm 0.3, p<0.001)$. However, it should be mentioned that the measurement of gastric $\mathrm{pH}$ does not reflect actual acid secretion, but actual acid content, which depends on peristalsis and is not directly influenced by pantoprazole. In a recent study, acid secretion was fully inhibited within $1 \mathrm{~h}$ after administration of $80 \mathrm{mg}$ of pantoprazole [7]. In the present study, an increase in $\mathrm{pH}$ usually occurred 30-45 min after administration. In some subjects, no increase in $\mathrm{pH}$ was seen in the observation period. This was ascribed to test conditions with subjects having fasted for at least $4 \mathrm{~h}$ and lying quietly on the left lateral decubitus during the observation period. These hampered or slowed down the emptying of the 

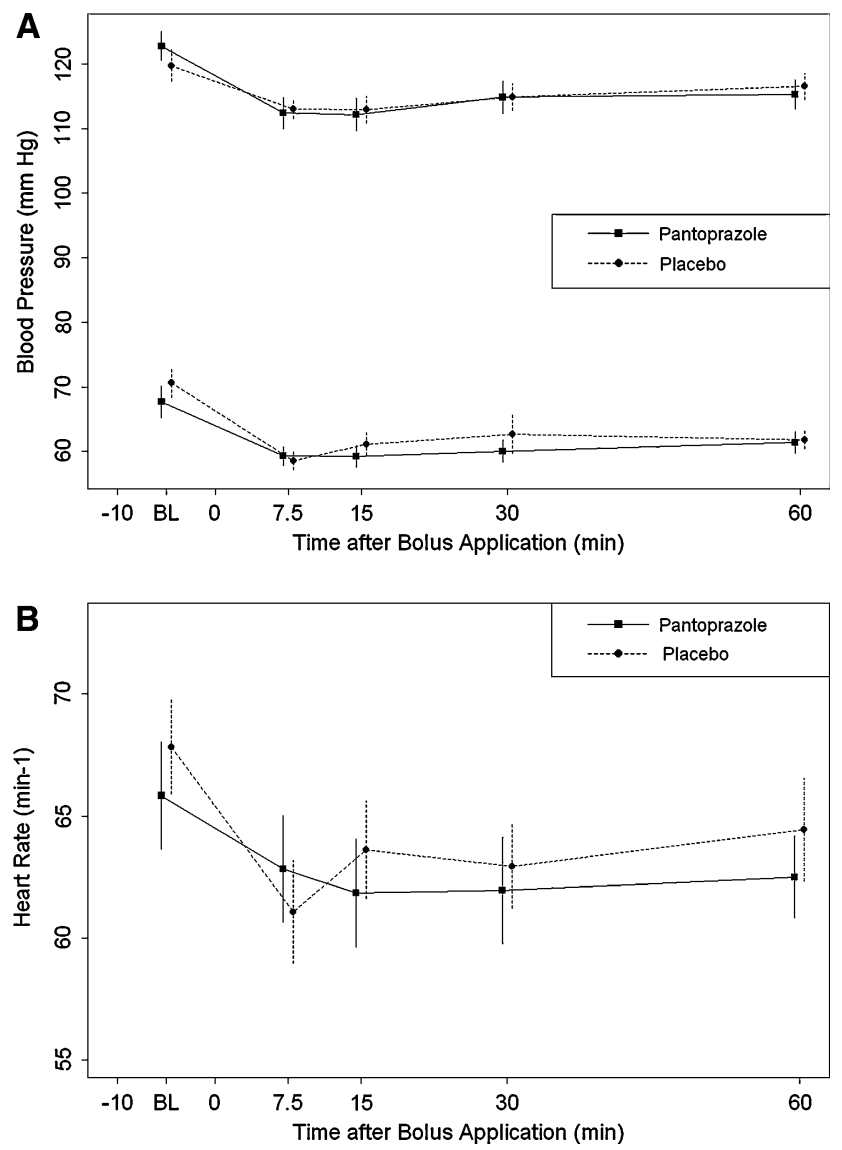

Fig. 2 Mean \pm SE of systolic and diastolic blood pressure (a) and of heart rate (b) at baseline (BL) and during application of a pantoprazole high-dose regimen (cf. "Materials and methods") as compared to placebo $(n=18$ each)

gastric acid to the duodenum. In other subjects receiving placebo, $\mathrm{pH}$ alternated between acidic and neutral values, reflecting temporal loss of contact of the $\mathrm{pH}$ catheter with gastric acid because of gastric peristalsis.

\section{Discussion}

The present study shows that a common high-dose regimen of pantoprazole $(80 \mathrm{mg}$ over $2 \mathrm{~min}$ followed by $8 \mathrm{mg} / \mathrm{h}$ i.v.), usually applied for reducing rebleeding after endoscopic treatment of bleeding peptic ulcers [30], did not result in clinically relevant impairment of left ventricular function and hemodynamics in healthy volunteers. We demonstrated that left ventricular EF did not significantly change over $60 \mathrm{~min}$ after application of pantoprazole as compared to baseline or to placebo. Also, no significant changes in cardiac output, cardiac index or any basic hemodynamic parameter were found. In contrast, gastric $\mathrm{pH}$ that was used as a treatment control was significantly increased $60 \mathrm{~min}$ after the application of pantoprazole as compared to baseline and to placebo.
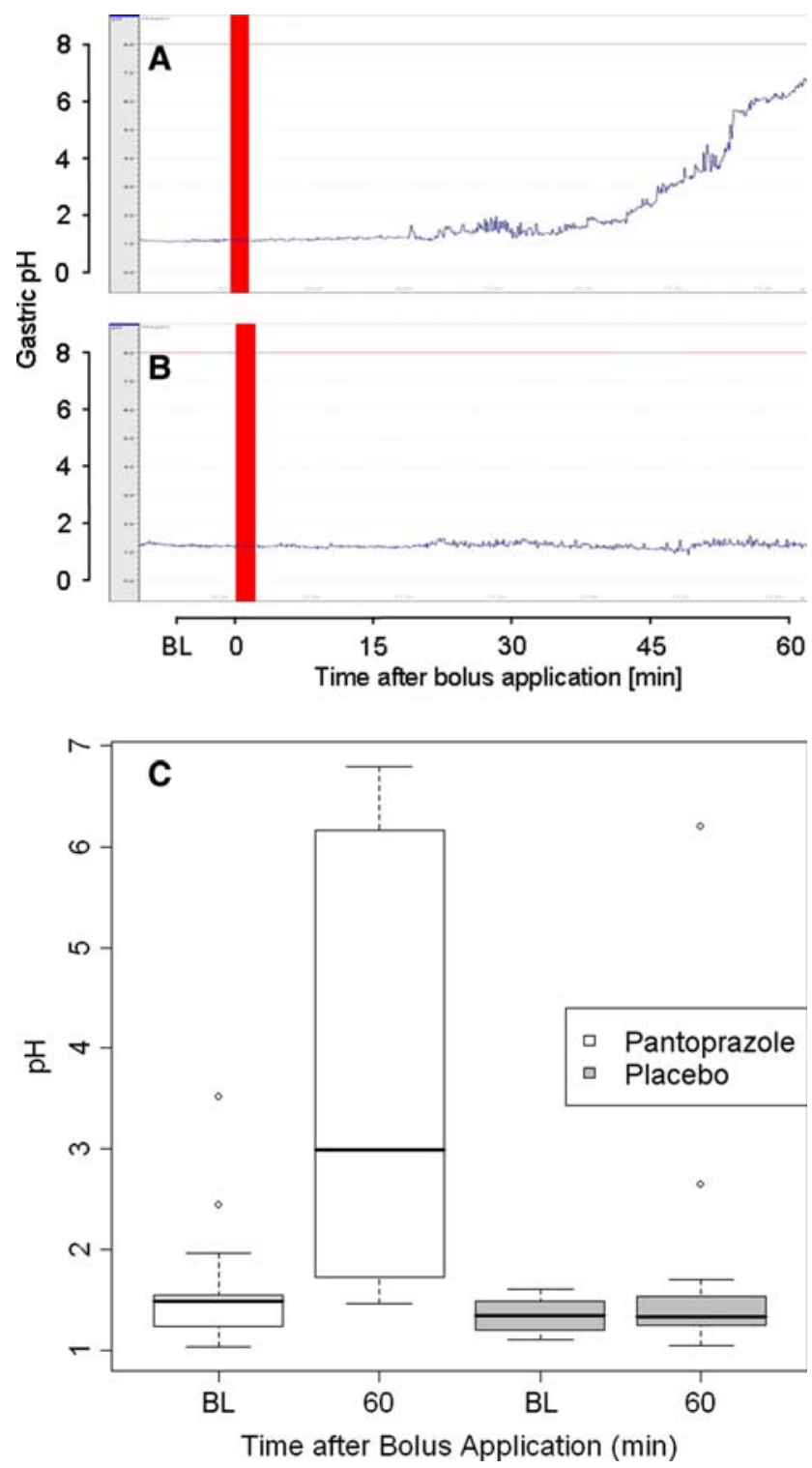

Fig. 3 Original recordings of typical gastric $\mathrm{pH}$ profiles of a healthy subject under treatment with pantoprazole (a) or placebo (b). c Box and whiskers plots showing median $\mathrm{pH}$ and $25-75 \%$ quartiles of gastric $\mathrm{pH}$ in healthy volunteers under treatment with pantoprazole or placebo at baseline (BL) and after $60 \mathrm{~min}$. Outliers are marked with circles $(n=18$ each $)$

\section{Pharmacology of PPIs}

With respect to gastric proton pump inhibition, all PPIs are prodrugs and require activation by protonation at low $\mathrm{pH}$. Following activation, PPIs undergo a series of chemical reactions that culminate in covalent binding to the gastric proton pump. Moreover, protonation converts the drug from a lipophilic to a hydrophilic form that can no longer permeate cell membranes. For these reasons, in parietal cells, PPIs become trapped after protonation and exhibit a substantial accumulation versus plasma at low $\mathrm{pH}$, making 
the inhibitory effect of PPIs on proton pumps independent of plasma concentrations [28]. Recently, our group has reported on negative inotropy of pantoprazole in isolated myocardium of humans and rabbits [25]. In contrast to the subcellular mechanisms of PPIs in gastric cells, the effects in myocardium were suggested to be independent of activation at low $\mathrm{pH}$, because negative inotropy occurred at $\mathrm{pH}$ 7.3-7.4. Moreover, in contrast to proton pump inhibition, the effects in the myocardium were at least partially reversible within few minutes after washout of the drug. Hence, we concluded that the potential effects of PPIs on contractile function in vivo may depend on plasma concentrations of the unprotonated native drug. However, in vivo PPIs are quickly eliminated from blood with plasma elimination half-lives of about 1-2 h [17, 26]. We therefore anticipated that in the present study, the potential impairment of left ventricular function during an identical infusion regimen of pantoprazole should be maximum at the time of maximum plasma concentrations, i.e., shortly after bolus application. For the same reason, no extended observations over several hours or days were performed in the present study.

Reasons for the absence of clinically relevant cardiac effects

What might be the potential reasons for the absence of a clinically relevant effect of pantoprazole on cardiac performance and hemodynamics in the present study in view of our recent findings in isolated myocardium? It is obvious that one has to be cautious in extrapolating in vitro findings to the clinical situation, because findings seen directly on the myocardial level may be masked in vivo by physiological effects such as preload, afterload, neurohumoral activation and heart rate. In this regard, it is noteworthy that heart rate was unchanged, which might have been indicative of an increased sympathetic tone as a compensatory mechanism. Moreover, cardiac side effects may be attenuated in vivo, because the activity of the free compound may be substantially lower because of high plasma protein binding. Recently, although $40 \mathrm{mg}$ pantoprazole gave a serum concentration-time curve (AUC) of the total parent compound of $10.5 \mu \mathrm{mol} \mathrm{h} / \mathrm{L}$, the high plasma protein binding of pantoprazole of $98 \%$ reversed the AUC value for the free drug to $0.19 \mu \mathrm{mol} \mathrm{h} / \mathrm{L}$ [17]. Yet, PPIs show characteristic pharmacokinetic properties that may specifically influence the potency of cardiac effects. For example, the fraction of drug unbound to plasma was reported as: omeprazole 0.05 , esomeprazole 0.05 , rabeprazole 0.04 , lansoprazole 0.03 and pantoprazole 0.02 [28]. Greater fraction of active free compound might therefore indicate superior potency with regard to cardiac effects.
Accuracy of methods

One might argue that the accuracy of echocardiography was not sufficient for the detection of small changes in left ventricular EF. However, during the last decades, echocardiographic methods and techniques have improved and expanded dramatically. It was shown that echocardiography can be performed with a high degree of reproducibility and that it was a reliable tool for the quantification of left ventricular function in numerous clinical trials [10, 18, 22]. Poor endocardial definition, the most frequent pitfall in 2D echocardiographic evaluation of left ventricular function $[10,18,22]$, was circumvented in the present study by only including subjects with excellent imaging conditions. Recently, in clinical trials, changes in left ventricular EF of 6-9\% were detected by echocardiography in patients with congestive heart failure under treatment with $\beta$-blockers, which have been considered as clinically relevant $[3,10$, 12]. The present study was powered to detect changes in left ventricular EF of at least $6 \%$ when calculation was done using published data. The true power of the present study using the standard deviations of the measured EFs was 0.98 . Thus, our study was sufficiently accurate to detect clinically relevant effects of a high-dose regimen of pantoprazole on left ventricular function.

\section{Implications for particular patients}

Although healthy subjects may well tolerate high doses of pantoprazole, particular patients may be prone to cardiac side effects of PPIs. In isolated human and rabbit myocardium, pantoprazole has been shown to affect the contractile force by two mechanisms: (1) reduction in the amplitude of $\mathrm{Ca}^{2+}$ transients as a consequence of impaired SR $\mathrm{Ca}^{2+}$ uptake and reduced $\mathrm{Ca}^{2+}$ influx via $\mathrm{I}_{\mathrm{Ca}, \mathrm{L}}$ (2) reduced $\mathrm{Ca}^{2+}$ responsiveness of the myofilaments as a result of a reduced maximal active tension and a slightly lower $\mathrm{Ca}^{2+}$ sensitivity [25]. In the end-stage failing human heart, development of contractile dysfunction is crucially caused by abnormalities of intracellular $\mathrm{Ca}^{2+}$ cycling and sarcomeric proteins. Decreased expression and function of SR $\mathrm{Ca}^{2+}-$ ATPase, increased forward mode $\mathrm{Na}^{+}-\mathrm{Ca}^{2+}$ exchange activity as well, as dysfunction of the ryanodine receptor promoting impairment of systolic and diastolic $\mathrm{Ca}^{2+}$ transients have been described [13]. Moreover, dysfunctions of myofilaments that are probably caused by altered post-translational modification, in particular the phosphorylation state of troponins I and $\mathrm{T}$ and possibly myosin light chain, have been found [20]. Hence, subcellular mechanisms underlying heart failure may be potentiated by treatment with high doses of pantoprazole. Further mechanisms of heart failure have been described $[2,5,15,24,29]$. Moreover, patients with heart failure are 
much more susceptible to negative inotropic drugs because of blunted contractile reserve subsequent to decreased sympathetic sensitivity [1] or negative force-frequency relationship [13]. Furthermore, certain patients may have considerably higher plasma concentrations of PPIs. All PPIs undergo extensive hepatic biotransformation before elimination. In CYP2C19-poor metabolizers that represent approximately $3-5 \%$ of Caucasians, a similar percentage of African-Americans and $12-25 \%$ of different Asian populations, much higher plasma concentrations and longer elimination half-lives have been found [28]. The same holds true for patients with severe liver impairment [8].

\section{Conclusions}

In conclusion, this study indicates that pantoprazole for injection is safe in healthy subjects with regard to cardiac contractile function when using a common high-dose regimen. Yet, it cannot be ruled out that ultra-high doses might impair function of normally beating hearts in vivo. Also, the effects of repetitive or continuous applications of high doses or application over prolonged periods have not been investigated for cardiac side effects in a prospective study. As long as there is no safety data, impairment of cardiac function should be taken into account in patients with heart failure or patients with combined heart and liver disease, as well as in particular situations like acute intoxication with ultra-high doses of pantoprazole. Moreover, in view of recent studies showing that appropriate use of intravenous PPIs was only seen in less than half of the patients [11, 16], treatment with intravenous PPIs should be discontinued as soon as the patient is able to be treated with oral formulations.

Acknowledgments We gratefully acknowledge the expert technical assistance of Mrs. Jutta Otto.

Conflict of interest statement The authors declare that they have no conflicts of interest in connection with the submitted article. The authors had full control of all primary data and agree to allow the journal to review their data if requested.

Open Access This article is distributed under the terms of the Creative Commons Attribution Noncommercial License which permits any noncommercial use, distribution, and reproduction in any medium, provided the original author(s) and source are credited.

\section{References}

1. Bristow MR, Ginsburg R, Minobe W, Cubicciotti RS, Sageman WS, Lurie K, Billingham ME, Harrison DC, Stinson EB (1982) Decreased catecholamine sensitivity and beta-adrenergic receptor density in failing human hearts. New Engl J Med 307:205-211
2. Dellas C, Hasenfuss G, Vollmann D (2007) Takotsubo cardiomyopathy with an unusual pattern of regional left ventricular wall motion abnormalities. Clin Res Cardiol 96:389-392

3. Doughty RN, Whalley GA, Gamble G, MacMahon S, Sharpe N (1997) Left ventricular remodeling with carvedilol in patients with congestive heart failure due to ischemic heart disease: Australia-New Zealand Heart Failure Research Collaborative Group. J Am Coll Cardiol 29:1060-1066

4. DuBois D, DuBois EF (1916) A formula to estimate the approximate surface area if height and weight be known. Arch Intern Med 17:863-871

5. Eschen O, Frøbert O, Jensen V, Hvitfeldt Poulsen S (2007) Pheochromocytoma, a rare cause of acute cardiogenic shock. Clin Res Cardiol 96:232-235

6. FDA statement (2007) FDA's safety reviews of Prilosec and Nexium find no evidence of increased rates of cardiac events. Available at http://www.fda.gov/bbs/topics/NEWS/2007/ NEW01754.html. Cited 10 December 2007

7. Ferron GM, McKeand W, Mayer PR (2001) Pharmacodynamic modeling of pantoprazole's irreversible effect on gastric acid secretion in humans and rats. J Clin Pharmacol 41:149-156

8. Ferron GM, Preston RA, Noveck RJ, Pockros P, Mayer P, Getsy J, Turner M, Abell M, Paul J (2001) Pharmacokinetics of pantoprazole in patients with moderate and severe hepatic dysfunction. Clin Ther 23:1180-1192

9. GKV (2008) Arzneimittelschnellinformation. Available at http:// www.gkv-gamsi.de/Archiv_2008_1_Quartal.gkvnet of subordinate document. Cited July 15, 2008

10. Gottdiener JS, Bednarz J, Devereux R, Gardin J, Klein A, Manning WJ, Morehead A, Kitzman D, Oh J, Quinones M, Schiller NB, Stein JH, Weissman NJ, American Society of Echocardiography (2004) American Society of Echocardiography recommendations for use of echocardiography in clinical trials. J Am Soc Echocardiogr 17:1086-1119

11. Guda NM, Noonan M, Kreiner MJ, Partington S, Vakil N (2004) Use of intravenous proton pump inhibitors in community practice: an explanation for the shortage? Am J Gastroenterol 99:1233-1237

12. Hall SA, Cigarroa CG, Marcoux L, Risser RC, Grayburn PA, Eichhorn EJ (1995) Time course of improvement in left ventricular function, mass and geometry in patients with congestive heart failure treated with beta-adrenergic blockade. J Am Coll Cardiol 25:1154-1161

13. Hasenfuss G, Pieske B (2002) Calcium cycling in congestive heart failure. J Mol Cell Cardiol 34:951-969

14. Himelman RB, Cassidy MM, Landzberg JS, Schiller NB (1988) Reproducibility of quantitative two-dimensional echocardiography. Am Heart J 115:425-431

15. Hoppe UC (2007) Treatment of heart failure with ACE inhibitors and beta-blockers: what is next? AT1-receptor antagonists? Clin Res Cardiol 96:196-198

16. Kaplan GG, Bates D, McDonald D, Panaccione R, Romagnuolo J (2005) Inappropriate use of intravenous pantoprazole: extent of the problem and successful solutions. Clin Gastroenterol Hepatol 3:1207-1214

17. Kromer W, Kruger U, Huber R, Hartmann M, Steinijans VW (1998) Differences in pH-dependent activation rates of substituted benzimidazoles and biological in vitro correlates. Pharmacology 56:57-70

18. Lang RM, Bierig M, Devereux RB, Flachskampf FA, Foster E, Pellikka PA, Picard MH, Roman MJ, Seward J, Shanewise JS, Solomon SD, Spencer KT, Sutton MS, Stewart WJ (2005) Recommendations for chamber quantification: a report from the American Society of Echocardiography's Guidelines and Standards Committee and the Chamber Quantification Writing Group, developed in conjunction with the European 
Association of Echocardiography. J Am Soc Echocardiogr 18:1440-1463

19. Lau JYW, Sung JJY, Lee KKC, Yung MY, Wong SK, Wu JC, Chan FK, Ng EK, You JH, Lee CW, Chan AC, Chung SC (2000) Effect of intravenous omeprazole on recurrent bleeding after endoscopic treatment of bleeding peptic ulcers. N Engl J Med 343:310-316

20. LeWinter MM (2005) Functional consequences of sarcomeric protein abnormalities in failing myocardium. Heart Fail Rev 10:249-257

21. Okabe S, Amagase K, Fujita H, Iwata K, Satake N, Shibata S (1996) Vasoinhibitory effect of leminoprazole, a H+, $\mathrm{K}(+)$ ATPase inhibitor, on rat aortic rings. Gen Pharmacol 27:117-121

22. Quiñones MA, Otto CM, Stoddard M, Waggoner A, Zoghbi WA (2002) Recommendations for quantification of Doppler echocardiography: a report from the Doppler Quantification Task Force of the Nomenclature and Standards Committee of the American Society of Echocardiography. J Am Soc Echocardiogr 15:167-184

23. Rhoden KJ, Tallini G, Douglas JS (1996) $\mathrm{H}^{+}-\mathrm{K}^{+}$ATPase inhibitors cause relaxation of guinea pig and human airway smooth muscle in vitro. J Pharmacol Exp Ther 276:897-903

24. Scharhag J, Herrmann M, Weissinger M, Herrmann W, Kindermann W (2007) N-terminal B-type natriuretic peptide concentrations are similarly increased by 30 minutes of moderate and brisk walking in patients with coronary artery disease. Clin Res Cardiol 96:218-226

25. Schillinger W, Teucher N, Sossalla S, Kettlewell S, Werner C, Raddatz D, Elgner A, Tenderich G, Pieske B, Ramadori G, Schöndube FA, Kögler H, Kockskämper J, Maier LS, Schwörer H, Smith GL, Hasenfuss G (2007) Negative inotropy of the gastric proton pump inhibitor pantoprazole in myocardium from humans and rabbits: evaluation of mechanisms. Circulation 116:57-66

26. Schulz M, Schmoldt A (2003) Therapeutic and toxic blood concentrations of more than 800 drugs and other xenobiotics. Pharmazie 58:447-474

27. Senn S (1993) Cross-over trials in clinical research. Wiley, Chichester

28. Shi S, Klotz U (2008) Proton pump inhibitors: an update on their clinical use and pharmacokinetics. Eur J Clin Pharmacol 64:935951

29. van der Horst IC, Voors AA, van Veldhuisen DJ (2007) Treatment of heart failure with ACE inhibitors and beta-blockers: what is next? Aldosterone receptor antagonists? Clin Res Cardiol 96:193-195

30. van Rensburg CJ, Hartmann M, Thorpe A, Venter L, Theron I, Lühmann R, Wurst W (2003) Intragastric pH during continuous infusion with pantoprazole in patients with bleeding peptic ulcer. Am J Gastroenterol 98:2635-2641 